\title{
A rare side effect of escitalopram: bilateral peripheral edema
}

\author{
Taha Can Tuman ${ }^{1}$, Bengü Tuman 2 \\ ${ }_{1}^{1}$ Birecik State Hospital, Department of Psychiatry, Birecik, Şanliurfa, Turkey. \\ 2 Birecik State Hospital, Department of Dermatology, Birecik, Sanliurfa, Turkey.
}

Received: 01/11/2018 - Accepted: 03/08/2018

DOI: 10.1590/0101-60830000000156

Tuman TC, Tuman B / Arch Clin Psychiatry. 2018;45(2):51-2

\section{Dear Editor,}

Escitalopram, S-isomer of sitalopram is well tolerated, rapid onset efficacy and used in the tratment of depression and other psychiatric disorders in elderly ${ }^{1-3}$. Escitalopram is highly serotonin specific and has minimal effect on the reuptake of other neurotransmitters 4 . Insomnia, headache, tremor, nausea, flushing, sweating, diarrhea, sexual dysfunction have been reported to be adverse drug reaction during escitalopram therapy $3,5,6$. In elderly patients, edema is an important health problem. Heart failure, renal failure, malabsorpsion, liver failure, allergic reactions, local inflammation and infections, burns, lymphatic obstruction increased capillary permeability, venous obstruction and drugs can cause peripheral edema ${ }^{7}$. Antihypertensive medications, nonsteroidal anti-inflammatory agents, calcium channel blockers, corticosteroids, hormones, antibiotics, beta blockers and direct vasodilators are drugs that often cause peripheral edema ${ }^{7,8}$. Edema has been reported rarely with psychiatric medications. Premarketing trials have reported peripheral edema as an infrequent adverse event which occured less than $1 / 100^{9}$. To the best of our knowladge, there are two case reports that edema associated with escitalopram. First, bilateral ankle edema in 69 year-old female patient after one month therapy with escitalopram $30 \mathrm{mg}$ per day, resolved within first week after discontinuation of the drug ${ }^{10}$. In second case, bilateral pedal edema associated with escitalopram $10 \mathrm{mg}$ per day developed 9th day of the treatment and resolved within 10 days after discontinuation of the drug ${ }^{11}$. Here, we report a case of bilateral leg edema on the 7 th day of the treatment with escitalopram $10 \mathrm{mg} /$ day and resolved within 12 days after discontinuation of the drug.

\section{Case}

A 71-year-old woman was presented with a three months history of lack of energy, loss of interest, hypersomnia, malaise and anxiety. We diagnosed major depression to the patient according to the DSM-IV criteria and we started escitalopram $10 \mathrm{mg} /$ day as an antidepressant medication. She was admitted to dermatology policlinics with bilateral edema on shins on 7 th day after escitalopram was started. On dermatological examination, there was swelling on the shins in both legs. Cellulite was not considered. There was no change of skin redness, ulceration and color. Results of renal function tests, thyroid function tests and liver function tests were within the normal limits. Blood electrolyte levels were normal. Echocardiogram and ECG findings were normal. There was no reason that could be found for edema. Escitalopram was reduced and stopped. After discontinuation of escitalopram, edema decreased. After 12 days, patient's legs were back to normal. Naranjo Adverse Drug Reaction Probability Scale was evaluated as 7 points a probable adverse effect associated with escitalopram ${ }^{12}$.

\section{Discussion}

Edema has been reported during treatment with various antidepressants such as mirtazapine, trazodone, tranylcypromine, phenelzine and isocarboxazid ${ }^{13-15}$. In literature, edema associated with escitalopram reported in two cases ${ }^{10-11}$. In first case, bilateral ankle edema may be associated with high dosage of escitalopram (30 mg per day) ${ }^{9}$. Higher dosages up to $20 \mathrm{mg}$ per day is not recommended by the pharmaceutical industry. In our case bilateral leg edema was developed in therapeutic doses. In first case with a 69-year-old depressed woman had been receiving atenolol and bromozepam for mild hypertension simultaneously with escitalopram ${ }^{10}$. In second case, 71 year-old patient with bilateral pedal edema had been receiving warfarin, bisoprolol and clonazepam simultaneously with escitalopram for atrial fibrillation and paroxysmal supraventricular tachcardia ${ }^{11}$. We know that drugs such as anxiolytics, antihypertensive drugs and beta blockers and comorbid diseases such as atrial fibrillation, hypertension and paroxysmal supraventricular tachcardia may have contributed to the development of peripheral edema in two cases reported in literature ${ }^{7}$. Therefore, these drugs may have contributed to the development of edema directly or via drug interaction in these cases. Unlike, there was no medication simultaneously with escitalopram and comorbid disease in our patient. Therefore, bilateral leg edema may be directly associated with escitalopram and no drug interactions was observed in our patient.

The possible etiology of edema with escitalopram may be due to increase in vascular permeability ${ }^{8}$. It may be an idiosyncratically drug reaction because of the strong serotonergic effects of escitalopram ${ }^{11}$.

Peripheral edema, a rare side effect due to escitalopram is reversible. Clinicians should be careful about this side effect because this side effect may occur at therapeutic doses and even if no medication and comorbid disease in patient's history.

\section{Acknowledgments}

Informed consent was obtained from the patient.

\section{Individual contributions}

All of the authors have participated and contributed to the treatment and follow-up of the patient and in writing the manuscript.

\section{Conflict of interest}

The authors declare no conflicts of interest.

\section{References}

1. Gorman JM, Korotzer A, Su G. Efficacy comparison of escitalopram and citalopram in the treatment of major depressive disorder: pooled analysis of placebo-controlled trials. CNS Spectr. 2002;7(4 Suppl 1):40-4.

2. Lepola UM, Loft H, Reines EH. Escitalopram (10-20 mg/day) is effective and well tolerated in a placebo-controlled study in depression in primary care. Int Clin Psychopharmacol. 2003;18(4):211-7.

3. Kasper S, de Swart H, Friis Andersen H. Escitalopram in the treatment of depressed elderly patients. Am J Geriatr Psychiatry. 2005;13(10):884-91.

4. Huska MT, Catalano G, Catalano MC. Serotonin syndrome associated with the use of escitalopram. CNS Spectr. 2007;12(4):270-4.

5. Moore N, Verdoux H, Fantino B. Prospective, multicentre, randomized, double-blind study of the efficacy of escitalopram versus citalopram in 
outpatient treatment of major depressive disorder. Int Clin Psychopharmacol. 2005;20(3):131-7.

6. Wade A, Michael Lemming O, Bang Hedegaard K. Escitalopram $10 \mathrm{mg} /$ day is effective and well tolerated in a placebo-controlled study in depression in primary care. Int Clin Psychopharmacol. 2002;17(3):95-102.

7. Cho S, Atwood JE. Peripheral edema. Am J Med. 2002;113(7):580-6.

8. Kaizu K, Abe M. Drug induced edema. Nihon Rinsho 2005;63:102-106.

9. Cipralex. Prescribing information. Disponível em: http://cipralex.com/ prescribing_information/default.aspx.

10. Masdrakis VG, Oulis P, Kouzoupis AV, Masdrakis GV, Soldatos CR. Bilateral ankle oedema in a patient taking escitalopram. World J Biol Psychiatry. 2009;10(4 Pt 3):939-41.
11. Ravi PB, Ravishankar GM, Andrade C. Bilateral peripheral edema as a rare adverse effect of escitalopram. Indian J Psychiatry. 2014;56(1):97.

12. Naranjo CA, Busto U, Sellers EM, Sandor P, Ruiz I, Roberts EA, et al. A method for estimating the probability of adverse drug reactions. Clin Pharmacol Ther. 1981;30(2):239-45.

13. Kutscher EC, Lund BC, Hartman BA. Peripheral edema associated with mirtazapine. Ann Pharmacother. 2001;35(11):1494-5.

14. Barrnett J, Frances A, Kocsis J, Brown R, Mann JJ. Peripheral edema associated with trazodone: a report of ten cases. J Clin Psychopharmacol. 1985;5(3):161-4.

15. Remick RA, Froese C, Keller FD. Common side effects associated with monoamine oxidase inhibitors. Prog Neuropsychopharmacol Biol Psychiatry. 1989;13(3-4):497-504. 